\title{
Reducing overcrowding in an emergency department: a pilot study
}

\author{
(iD) Fábio Ferreira Amorim ${ }^{1}$ \\ D Karlo Jozefo Quadros de Almeida ${ }^{1}$ \\ (iD) Sanderson Cesar Macedo Barbalho \\ [D Vanessa de Amorim Teixeira Balieiro ${ }^{1}$ \\ (iD) Arnaldo Machado Neto ${ }^{1}$ \\ (iD) Guilherme de Freitas Dias ${ }^{1}$ \\ (iD) Levy Aniceto Santana ${ }^{1}$ \\ Cristhiane Pinheiro Teixeira Gico de Aguiar ${ }^{3}$ \\ (iD) Cláudia Cardoso Gomes da Silva ${ }^{1}$ \\ (iD) Sriram Dasu ${ }^{4}$
}

\begin{abstract}
1. Escola Superior de Ciências da Saúde, Brasília, DF, Brasil. 2. Universidade de Brasília, Brasília (DF). Centro de Apoio e Desenvolvimento Tecnológico - Campus Universitário Darcy Ribeiro, Brasília, DF, Brasil. 3. Secretaria de Estado de Saúde do Distrito Federal, Brasília, DF, Brasil.

4. University of Southern California, USA.
\end{abstract}

http://dx.doi.org/10.1590/1806-9282.65.12.1476

\section{SUMMARY}

OBJECTIVE: Exploring the use of forecasting models and simulation tools to estimate demand and reduce the waiting time of patients in Emergency Departments (EDs).

METHODS: The analysis was based on data collected in May 2013 in the ED of Recanto das Emas, Federal District, Brasil, which uses a Manchester Triage System. A total of 100 consecutive patients were included: 70 yellow (70\%) and 30 green (30\%). Flow patterns, observed waiting time, and inter-arrival times of patients were collected. Process maps, demand, and capacity data were used to build a simulation, which was calibrated against the observed flow times. What-if analysis was conducted to reduce waiting times.

RESULTS: Green and yellow patient arrival-time patterns were similar, but inter-arrival times were 5 and 38 minutes, respectively. Waittime was 14 minutes for yellow patients, and 4 hours for green patients. The physician staff comprised four doctors per shift. A simulation predicted that allocating one more doctor per shift would reduce wait-time to 2.5 hours for green patients, with a small impact in yellow patients' wait-time. Maintaining four doctors and allocating one doctor exclusively for green patients would reduce the waiting time to 1.5 hours for green patients and increase it in 15 minutes for yellow patients. The best simulation scenario employed five doctors per shift, with two doctors exclusively for green patients.

CONCLUSION: Waiting times can be reduced by balancing the allocation of doctors to green and yellow patients and matching the availability of doctors to forecasted demand patterns. Simulations of EDs' can be used to generate and test solutions to decrease overcrowding.

KEYWORDS: Time Management, Emergency Medical Services, Computer Simulation, Health Services Needs and Demand, Patient Satisfaction. 


\section{INTRODUCTION}

The primary concern of (medical) emergency departments (EDs) is the ability to provide timely and effective care. ${ }^{1-5}$ However, the operations of EDs are highly complex, and the ability of the staff to provide good care is affected by many factors. Overcrowding is one such factor and a very common problem that EDs face worldwide. It reduces the quality of care, worsens the work environment, increases the time necessary to initiate appropriate patient treatment, and raises the cost of the healthcare system. ${ }^{1-3,6}$

The number of patients entering EDs at a given time is the greatest factor influencing wait-times for an initial consultation, as well as an individual's total time in an ED. The performance of the ED can also be exacerbated by other factors such as the mismanagement of patient flows, lack of access to inpatient beds, demand from patients for specialized care instead of primary care, absence of or reduced access to primary care, and structural failure of the healthcare system to manage population health. ${ }^{2,6,7}$

While overcrowding is a widespread problem, it follows a predictable pattern-across hours, days, weeks, months, and seasons-of patients arriving at EDs. ${ }^{2}$ With the capabilities of information technology, it is possible to both understand this pattern and build simulation tools that can assist managers of healthcare systems. These tools can predict demand and wait times, which would help managers plan human resources and alter processes and patient flows to improve the quality of care while respecting budget constraints. Furthermore, these tools can be used to train staff and inform patients, thereby further improving the performance of EDs. ${ }^{1,2,4,6}$

The main purpose of this study was to build a forecasting model and a simulation tool that would predict the demand and waiting time of patients in an ED, assist in human resource planning, process design, guide educational strategies for staff, and improve the decision-making processes of healthcare managers.

\section{METHODS}

This study is based on data collected in May 2013 in the ED of Recanto das Emas, Federal District, Brasil, which is a public ED of the Brazilian Single Health System (SUS). The Manchester Triage System (MTS) was used to triage patients. In the MTS, different colors indicate the level of urgency and its associated maximum wait time. The colors and their respective levels of urgency are as follows: red, immediate care by a physician (0 minutes); orange, very urgent (10 minutes); yellow, urgent (60 minutes); green, standard care (2 hours); blue, non-urgent care (4 hours). ${ }^{8}$

The following method was employed in this study.

Step A - Data collection: In this step, the following information was collected

1) Mapping of the general process of patient flows for yellow and green levels (figure 1);

2) Collection of arrival and processing times. This was done over six consecutive days.

3) Availability of physicians. This information was obtained from physicians' work schedules

Step B: Model development and validations

The data collected was used to develop the following:

Flow patterns of patients through the ED for each patient class (MTS color),

Observed waiting time in the ED (the length of time when the patient is waiting for a physician),

Inter-arrival times (the time-gap between arrivals of two consecutive patients in the ED), and the distribution of the number of arrivals during the period of a day were determined (figure 2).

The process maps, demand, and capacity data were used to build a simulation tool in Simul8.

The simulation output was calibrated against the observed flow times, and what-if analyses were conducted to reduce waiting times

FIGURE 1. MAPPING OF THE GENERAL PROCESS OF PATIENT FLOWS FOR YELLOW AND GREEN LEVELS IN THE EMERGENCY DEPARTMENT OF RECANTO DAS EMAS, FEDERAL DISTRICT, BRASIL.

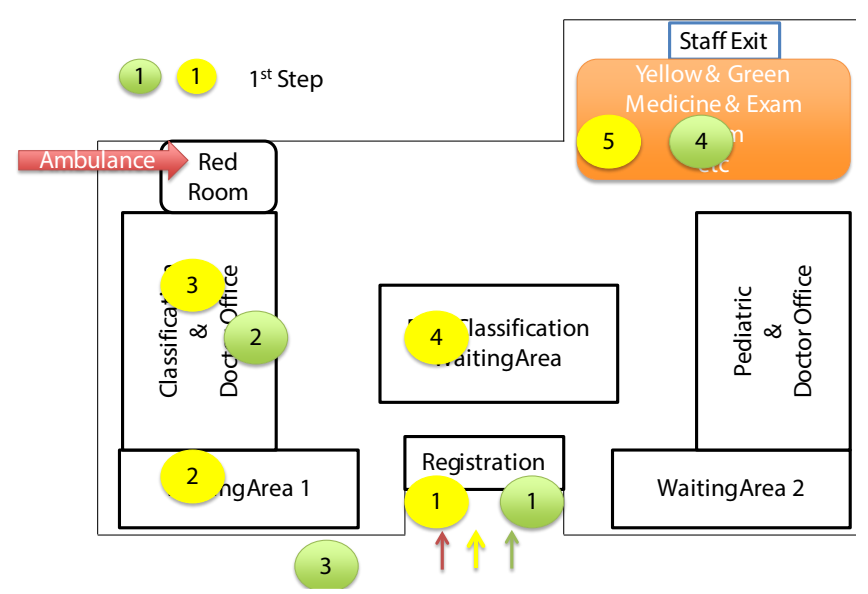




\section{RESULTS}

The process maps and the simulation tool yielded the following findings. (figure 1):

1. Entry to the System: After a patient enters the system, they register at the front desk, where administrators and a nurse are present. That nurse's function is to identify emergency care patients that should be taken directly to the "red room" where a "red doctor" works as a dedicated resource. Other walk-in patients wait an average of 20 minutes before being further triaged by a nurse practitioner. The nurse assesses the MTS level and routes the patient.

2. Initial Triage and Perceived Lack of Progress: Of approximately 300 patients per day that enter the UPA system, approximately 210 patients are green, approximately 35 are yellow, and the remainder are blue, orange, or red patients. Green patients get classified and, instead of moving forward to the Post-Classification Waiting Area, they return to the Waiting Area \#1 or \#2. The area allocated to green patients is small, leading to crowding. The green patients feel they are not moving through the system, which leads them to believe they are not important.

3. Consultations with a Physician and Delays: For each 8-hour shift, there are six doctors on call. One is dedicated to pediatrics. One is dedicated to the red-level. One is dedicated to yellow patients in the "yellow room" (patients with more urgent needs, staying in the system, or in need of a transfer to the hospital). The three remaining doctors are stationed in the Classification Doctors Office area. These three doctors diagnose patients after classification and control the flow subsequently in the system. Due to the priority label given to

FIGURE 2. DISTRIBUTION OF THE NUMBER OF ARRIVALS DURING THE DAY AND TIME SPENT DURING A CONSULTATION FOR YELLOW AND GREEN LEVELS IN THE EMERGENCY DEPARTMENT OF RECANTO DAS EMAS, FEDERAL DISTRICT, BRASIL.

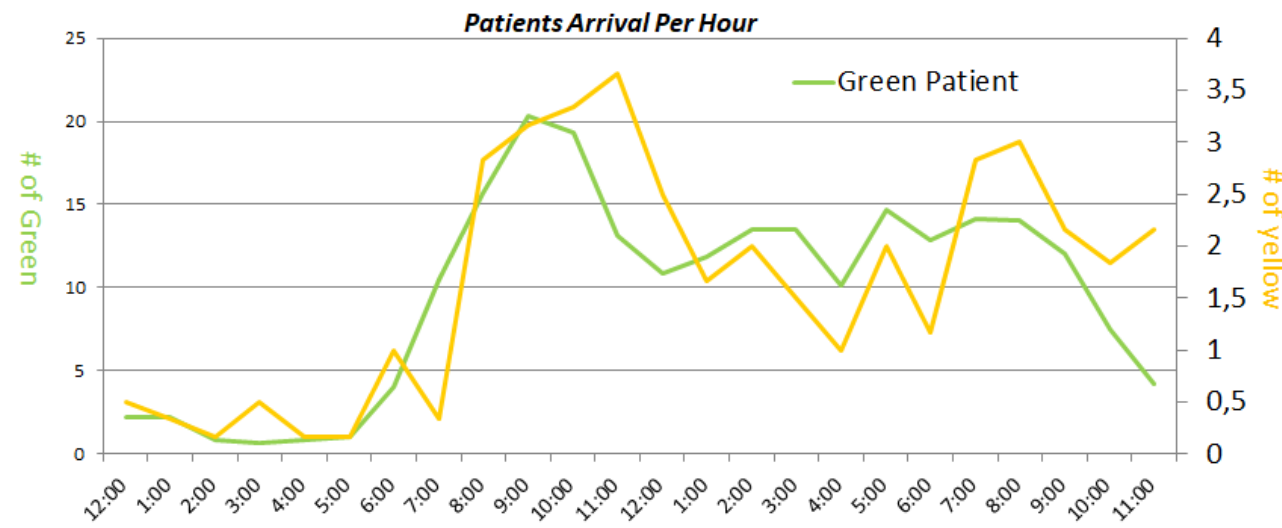

(a)

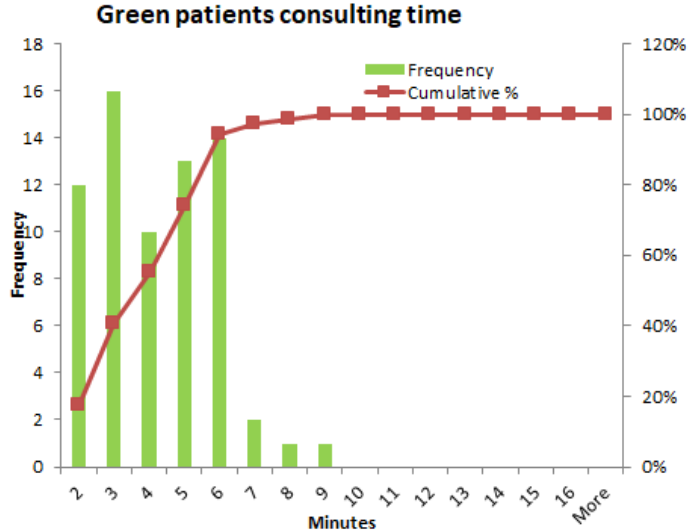

(b)

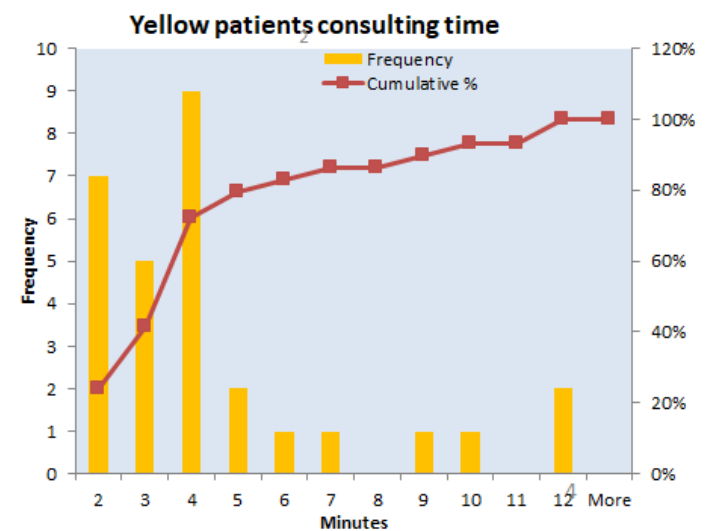

(c) 
yellow patients, green patients may, on average, spend to up to two hours waiting to see a doctor, and four hours in the system, while yellow patients typically get seen within 20 minutes and move through the system at a quicker rate.

To address the problems identified above, the following solutions were proposed.

1. Initial Triage and Lack of Progress: One possible solution to address green patients' dissatisfaction is to create a dual-door system out of the nurse's Classification Office. The entry and exit doors would be different, as would in the waiting area. This could create a sense of progress.

2. Consultation with a Physician and Delays: The number of arrivals per hour was determined across all six days for green and yellow patients separately. The data shows that the arrival patterns according to the time of the day, both for yellow and green levels. The study included 100 consecutive patients: 70 yellow patients (70.0\%) and 30 green patients (30\%). The data shows that green and yellow patient hourly arrival patterns are similar across all days. For yellow patients, 9:00-11:00 a.m. was the peak arrival time, and 8:00-10:00 a.m. was the peak arrival time for green patients (figure 2).

The mean inter-arrival time was 38 minutes for yellow patients, and 5 minutes for green patients. In the period of the study, the ED had a physician staff of four doctors per shift, at all times. The mean waittime was 14 minutes for yellow patients, and 4 hours for green patients (table 1). The time spent during a consultation with a doctor was 4.3 minutes for yellow patients and 4.1 minutes for green patients (figure 2).

A simulation model was built to conduct what-if analysis. The alternatives considered were (a) adding more physicians and (b) changing priorities.

(a) Adding an extra physician: The simulation model predicts that allocating one more doctor per shift (i.e., five doctors per shift) would be associated with a reduction in the average wait-time of 2.5 hours for green patients, as well as a small reduction in the average wait-time for yellow patients.

(b) Retaining the same 4 physicians but dedicating one to the green area: maintaining four doctors and allocating one exclusively for green patients would be associated with a reduction in the average waiting time of 1.5 hours for green patients and an increase in the average waiting time of 15 minutes for yellow patients,

(c) Adding an extra physician and dedicating two to the green area: this scenario employed five doctors per shift with two doctors allocated exclusively for green patients. In this scenario, the average waiting time was reduced to 2.8 hours for green patients and increased by 7 minutes for yellow patients (table 1).

TABLE 1. SIMULATION MODEL USED TO CONDUCT WHAT-IF ANALYSIS IN THE EMERGENCY DEPARTMENT OF RECANTO DAS EMAS, FEDERAL DISTRICT, BRASIL.

\begin{tabular}{|c|c|c|}
\hline \multirow{3}{*}{ 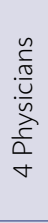 } & $\begin{array}{l}\text { No Dedicated "Green" Doctor } \\
\text { (Status Quo) }\end{array}$ & 1 Dedicated "Green" Doctor \\
\hline & Yellow waiting time: 14 min & Yellow waiting time: 29 min \\
\hline & Green waiting time: 4 hours & $\begin{array}{l}\text { Green waiting time: } 2.5 \\
\text { hours }\end{array}$ \\
\hline \multirow{3}{*}{ 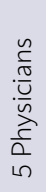 } & No Dedicated "Green" Doctor & 2 Dedicated "Green" Doctors \\
\hline & Yellow waiting time: 15 min & Yellow waiting time: $21 \mathrm{~min}$ \\
\hline & Green waiting time: 1.5 hours & Green waiting time: 1.2 hours \\
\hline
\end{tabular}

Assumption: $80 / 20$ split: $80 \%$ of green patients go to dedicated green doctors. Inter-arrival time: "green" every 5 minutes vs. "yellow" every 38 minutes. Average doctor consultation time: 10 minutes for both "green" \& "yellow" patients

\section{DISCUSSION}

The performance of healthcare services is under constant scrutiny. A dramatic increase in EDs visit rates-a global phenomenon-has led to overcrowding, long waiting times, and delays in critical treatments. This has become a major problem for health care managers, as a patient's wait-time is one of the most important factors in health care management and a great determinant of patients' satisfaction. 2,3-6,10,11 Because of this, the need for improvement in EDs with regards to overcrowding and patient satisfaction is broadly accepted. ${ }^{9}$ Data-driven analysis has been used successfully to improve patient flow in EDs. The resulting improvements consist of optimal provisioning of available resources. ${ }^{12}$ Healthcare managers can adjust staffing and flow rules based on the observed patterns and experience substantial improvement in the ED's performance. .,2,4,6,9,12 $^{2}$

In this study, we used sample data to model the arrival rates, flow patterns, and processing times. This was used to set up a simulation model that can predict the impact of different staffing and flow control 
rules on the wait-time in the ED for different patient classes. This enables healthcare managers to generate and evaluate solutions to improve the current overcrowding situation under different scenarios.

In the present study, although yellow patients were being seen within the wait-time recommended by the MTS, the average wait-time for green patients was twice as long as recommended by the MTS. A simulation tool was used to evaluate solutions that would reduce the waiting time for green patients. The most effective solution, which ensured no increase in the waiting time for yellow patients and brought the green waiting time down to conformance levels, employed five doctors per shift with two of those doctors allocated exclusively for green patients. ${ }^{8}$ This analysis brings into sharp focus the trade-offs between the cost of additional resources and improved patient experience.

If increasing the staff to five doctors is not possible, the simulation tool suggests that allocating a single doctor exclusively for green patients would be associated with a reduction in the average wait-time of 1.5 hours for green patients, while maintaining the wait-time for yellows patients under 60 minutes-the maximum waiting time suggested by MTS. ${ }^{8}$ The analysis also shows that priority rules can also alter the performance. In other words, even without adding resources, by managing the flows carefully, it is possible to yield significant improvements. This illustrates the importance of using data to develop optimal flow management rules, especially in budget-constrained environments where adding resources is not feasible.

Ideally, the human resources of an ED need to match the workload as dictated by patients' arrival-time patterns. ${ }^{1,2,6,13}$. A mismatch between the arrival rates of patients and the number of employees on staff can be a major contributing factor to overcrowding and prolonged wait-times in EDs. ${ }^{1,6,13}$. In this study, a pattern of patients' arrival time was observed with peaks in the morning and trough at night. This pattern is similar to that of other studies. ${ }^{6,14-16}$ The patients' arrival pattern suggests that the relocation of one doctor from the night-shift to the day-shift could also improve the wait-time without requiring additional human resources.

One of the main limitations of the study is its small sample size and short duration. Indeed, it should be highlighted that having a simulation tool and implementing it to alter clinical practice are two different things. In this case, this tool has only been tested in simulation scenarios and, consequently, the researchers will need to determine if it has an impact on clinical care. The next step is to apply the simulation tool as an automated system to predict wait-times and to manage patient flow on a real-time basis in an ED. In this case, the patients would be able to see the ED waiting times online. This information can help patients arrive at the ED during less-crowded hours. ${ }^{17}$ Reduced waiting times not only increase patient satisfaction but will also enhance patient safety. Previous studies have shown an association between ED overcrowding and an increase in patients departing from the EDs without being seen by a physician, as well as adverse events such as medication errors and infection transmissions. ${ }^{18-22}$

\section{CONCLUSION}

Data-driven analysis can be used to assist healthcare managers in providing solutions to improve the current overcrowding situation. Data can be used to carefully balance resource availability with patient arrivals. This may entail changing staffing levels and rules used to manage flows. For example, the most effective of the different scenarios to reduce the extremely high wait-times for green patients - without increasing the wait-times for yellow patients-was to employ five doctors per shift, with two of those doctors allocated exclusively for green patients. Also, shifting some capacity from relative slow evening periods to busier mornings can sharply reduce waiting times. Overcrowding can also be reduced by influencing arrival patterns. For example, a real-time tool that predicts waiting times can be used to inform patients. This, in turn, can cause the peak load to dissipate.

We observed some fragilities of the system that impact the patients' perception of their value. This example illustrates that patient satisfaction can also depend on subjective factors. As discussed, one possible solution to improve patient experience is to create a dual-door system at the nurse's Classification Office. This would help patients feel that they are moving forward in the system, and therefore are important.

This work shows that data analysis can facilitate optimal staffing and management of flows. In resource-constrained environments where adding resources is not easy, optimal usage of staff is crucial. Balancing the scheduling of available doctors to hourly demand patterns and allocating the right number of doctors to green and yellow patients can diminish waiting times and improve patient safety, even without increasing staffing levels. Hence, the analysis also 
illustrates the importance of leveraging data and creating digitally ready emergency departments, especially in resource-constrained environments.

\author{
Acknowledgments \\ This Research was funded by the Institutional
}

\author{
Research Grant Program from the Fundação de Ensino \\ e Pesquisa em Ciências da Saúde, Brasília, Distrito \\ Federal, Brasil.
}

\section{Conflicts of interest \\ None.}

\section{RESUMO}

OBJETIVO: Explorar o uso de modelos de previsão e ferramentas de simulação para estimar a demanda e reduzir o tempo de espera dos pacientes em Departamentos de Emergência (DE).

METODOLOGIA: A análise foi baseada em dados coletados em maio de 2013, no DE do Recanto das Emas, Distrito Federal, Brasil, que utiliza o Protocolo de Manchester como sistema de triagem. Um total de 100 pacientes consecutivos foram incluídos: 70 amarelos (70\%) e 30 verdes (30\%). Padrões de fluxo, tempo de espera observado e tempos entre as chegadas dos pacientes foram registrados. Mapas de processo, demanda e dados de capacidade foram utilizados na construção de uma simulação que foi calibrada de acordo com o fluxo observado. Uma análise do tipo "e se..." foi conduzida para reduzir os tempos de espera.

RESULTADOS: Os padrões de tempo de chegada para pacientes verdes e amarelos foram semelhantes, mas os tempos entre chegadas foram 5 e 38 minutos, respectivamente. O tempo de espera foi de 14 minutos para pacientes amarelos e 4 horas para pacientes verdes. A equipe médica era composta por quatro médicos por turno. Uma simulação previu que a inclusão de mais um médico por turno reduziria o tempo de espera para 2,5 horas para pacientes verdes, com um impacto pequeno no tempo de espera dos pacientes amarelos. A manutenção de quatro médicos e a inclusão de um médico exclusivamente para pacientes verdes reduziria o tempo de espera para 1,5 horas para pacientes verdes e aumentaria em 15 minutos para os pacientes amarelos. O melhor cenário simulado utilizou cinco médicos por plantão, com dois médicos exclusivos para pacientes verdes.

CONCLUSÃO: Os tempos de espera podem ser reduzidos equilibrando a distribuição de médicos para pacientes verdes e amarelos e relacionando a disponibilidade dos médicos aos padrões de demanda previstos. Simulações de DE podem ser utilizadas para gerar e testar soluções para diminuir a superlotação.

PAlaVRAS-CHAVE: Gerenciamento de Tempo, Serviços Médicos de Emergência, Simulação por Computador, Necessidades e Demandas de Serviços de Saúde, Satisfação do Paciente.

\section{REFERENCES}

1. Anderson D, Pimentel L, Golden B, Wasil E, Hirshon JM. Drivers of ED efficiency: a statistical and cluster analysis of volume, staffing, and operations. Am J Emerg Med. 2016; 34(2):155-61.

2. Crade J, Noon C. The definitive guide to emergency department operational improvement: employing lean principles with current ED best practices to create the "no wait" department. 1. ed. New York: Productivity Press, 2011.

3. Pines |M, Hilton |A, Weber E|, Alkemade A|, Al Shabanah H, Anderson PD et. al. International perspectives on emergency department crowding. Acad Emerg Med. 2011; 18(12):1358-70.

4. Ajami S, Ketabi S, Yarmohammadian MH, Bagherian H. Wait Time in Emergency Department (ED) Processes. Med Arh. 2012; 66(1):53-7.

5. Choyce MQ, Maitra AK. Satisfaction with the Accident and Emergency Department, a Postal Survey of General Pracitioners' Views. J Accid Emerg Med. 1996; 13(4):280-2.

6. Tiwari $Y$, Goel S, Singh A. Arrival time pattern and waiting time distribution of patients in the emergency outpatient department of a tertiary level health care institution of North India. J Emerg Trauma Shock. 2014; 7(3):160-5.

7. Harris A, Sharma A. Access block and overcrowding in emergency departments: an empirical analysis. Emerg Med J. 2010; 27(7):508-11.

8. Mackway-Jones K, Marsden J, Windle J (Eds.). Emergency Triage: Manchester Triage Group. 3. ed. Massachussets: Wiley Blackwell, 2013.

9. Holden RJ. Lean Thinking in emergency departments: a critical review. Ann Emerg Med. 2011; 57(3):265-78.

10. Higginson I. Emergency department crowding. Emerg Med J. 2012; 29(6):437-43.

11. Cooke M. Emergency medicine. Whole system is responsible for solving overcrowding of departments. BMJ. 2002; 325(7360):389.
12. Lovett PB, IIIg ML, Sweeney BE. A Successful Model for a Comprehensive Patient Flow Management Center at an Academic Health System. Am J Med Qual. 2016; 31(3):246-55.

13. Singer AJ, Thode HC Jr, Viccellio P, Pines |M. The Association Between Length of Emergency Department Boarding and Mortality.Acad Emerg Med. 2011; 18(12):1324-9.

14. Goel S, Singh A. Will plague continue to haunt hilly states of India? The Internet J Health. 2007; 8(1):18-23.

15. Chan L, Reilly KM, Salluzzo RF. Variables that affect patient through put times in an academic emergency department. Am J Med Qual. 1997; 12(4):183-6.

16. Ay $D$, Akkas M, Sivri B. Patient population and factors determining length of stay in adult ED of a Turkish University Medical Center. Am J Emerg Med. 2010; 28(3):325-30.

17. [No authors listed]. Patients in Northern Ireland can see waiting times online. Emerg Nurse. 2015; 23(7):6.

18. Kulstad EB, Sikka R, Sweis RT, Kelley KM, Rzechula KH. ED overcrowding is associated with an increased frequency of medication errors. Am J Emerg Med. 2010; 28(3):304-9

19. Goel S, Gupta AK, Singh A, Lenka SR. Preparations and limitations for prevention of severe acute respiratory syndrome in a tertiary care centre of India. J Hosp Infect. 2007; 66(2):142-7.

20. Monzon J, Friedman SM, Clarke C, Arenovich T. Patients who leave the emergency department without being seen by a physician: a control-matched study. CJEM. 2005; 7(2):107-13.

21. Weiss S), Ernst AA, Derlet R, King R, Bair A, Nick TG. Relationship between the national ED overcrowding scale and the number of patients who leave without being seen in an academic ED. Am J Emerg Med. 2005; 23(3):288-94. 